\title{
Commentary: Humanitarian outreach-Providing resources and measuring quality
}

\author{
Jeffrey P. Jacobs, MD, ${ }^{\mathrm{a}}$ James D. St Louis, MD, ${ }^{\mathrm{b}}$ and Frank G. Scholl, MD ${ }^{\mathrm{a}, \mathrm{c}}$
}

\footnotetext{
From the ${ }^{\mathrm{a} C a r d i a c}$ Kids Foundation of Florida, Saint Petersburg, Fla; ${ }^{\mathrm{b}}$ Department of Surgery, University of Missouri-Kansas City School of Medicine, Kansas City Mo; and ${ }^{\mathrm{c} D e p a r t m e n t ~ o f ~ S u r g e r y, ~ J o e ~ D i M a g g i o ~ C h i l-~}$ dren's Hospital, Hollywood, Fla.

Disclosures: Authors have nothing to disclose with regard to commercial support.

Received for publication May 1, 2019; accepted for publication May 3, 2019; available ahead of print June 27, 2019.

Address for reprints: Jeffrey P. Jacobs, MD, 2021 Brightwaters Blvd, Saint Petersburg, FL 33704 (E-mail: JeffJacobs@msn.com).

J Thorac Cardiovasc Surg 2020;159:1000-1

$0022-5223 / \$ 36.00$

Copyright (c) 2019 Published by Elsevier Inc. on behalf of The American Association for Thoracic Surgery https://doi.org/10.1016/j.jtcvs.2019.05.014
}

Vervoort and colleagues ${ }^{1}$ are to be congratulated for their article in this issue of the Journal, "Global Cardiac Surgery: Access to Cardiac Surgical Care Around the World."1 This article presents an analysis performed by the Program in Global Surgery and Social Change at Harvard Medical School, Boston, Massachusetts. A scoping review was done to identify quantitative data and descriptive studies on worldwide access to cardiac surgical care with a focus on cardiac surgical workforce, infrastructure, capacity, and quality. A scoping review, or scoping study, is defined as "a rapid gathering of literature in a given policy or clinical area where the aims are to accumulate as much evidence as possible and map the results." 2 The central message of the article of Vervoort and colleagues ${ }^{1}$ is that " 4.5 billion people lack access to cardiac surgery when needed. Availability of adult and pediatric cardiac surgical workforce is scarce in low- and middle-income countries, and disparities are widespread.'

As professionals dedicated to cardiothoracic care, we have the responsibility to minimize these global disparities in access to cardiothoracic surgery. Two critical areas in which efforts are ongoing to address these disparities are (1) global availability of cardiothoracic surgical resources and (2) global assessment of quality of cardiothoracic care. Examination of some of these ongoing efforts demonstrates that substantial effort is underway, but much work remains to be done.

Multiple governmental and nongovernmental organizations (NGOs) dedicate substantial time and effort to providing cardiothoracic care in developing countries. Several NGOs sponsor cardiothoracic surgical missions in multiple developing countries, as exemplified by Children's HeartLink (https://childrensheartlink.org/), Chain of Hope (https://www.chainofhope.org/), and Gift of Life International (http://www.giftoflifeinternational.org/). ${ }^{3}$ Many of these NGOs focus on creating sustainable cardiothoracic surgical programs in developing countries through the use

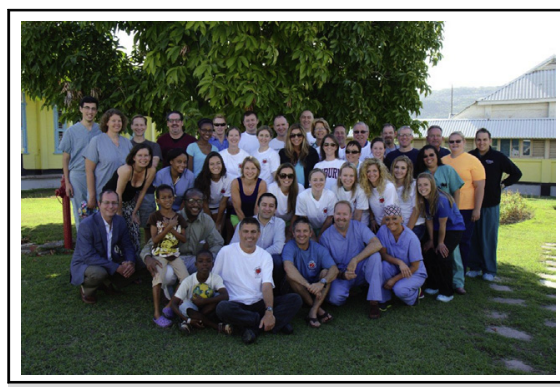

"It takes a village": multidisciplinary team in Kingston, Jamaica, in 2014

Central Message

We have the responsibility to minimize global disparities in access to cardiothoracic surgery by addressing both (1) availability of cardiothoracic surgical resources and (2) assessment of quality of cardiothoracic care.

See Article page 987.

of "twinning programs," 4,5 which match a potential partner site in the developing world with a seasoned, reputable cardiothoracic team from elsewhere in the world. "Twinning is the pairing of two cardiac programs (one an established center of excellence and the other an evolving program in the developing world) to establish a relationship of value to both organizations. In those countries where maldistribution of access is the main problem, the existing centers of excellence can contribute to the creation and support of new centers-_"national twinning programs." International twinning programs are necessary in countries without existing centers of excellence capable of providing support." 5

Professional medical and surgical societies can also provide resources to address the global disparities in cardiothoracic care. This strategy is exemplified by The Thoracic Surgery Foundation (https://thoracicsurgery foundation.org/) and its partnership with Edwards Lifesciences (https://www.edwards.com/aboutus/heartbeat). Since 2014, because of Every Heartbeat Matters:

- Sixty nonprofit partners joined the initiative.

- Approximately 900,000 underserved people have been affected by public health education.

- More than 17,000 clinicians caring for underserved patients have received training. 
- More than 80,000 underserved people have been screened for heart valve disease.

- Nearly 5000 underserved people have received heart valve treatment.

- The initiative has reached underserved people in 36 countries.

Finally, it is crucial to assess and improve the quality of cardiothoracic care in all programs, including those in developing nations. Many tools are available that support this objective, as exemplified by the following programs that have been developed and operationalized globally ${ }^{6,7}$ :

- The International Quality Improvement Collaborative for Congenital Heart Surgery in Developing World Countries was founded by representatives from Boston Children's Hospital in collaboration with NGOs to form a quality improvement collaborative focused on evaluating performance and driving improvement efforts for the care of patients with pediatric and congenital heart disease in settings with limited resources.

- The World Database for Pediatric and Congenital Heart Surgery was created by members of The World Society for Pediatric and Congenital Heart Surgery to "promote the highest quality of comprehensive cardiac care to all patients with congenital heart disease."

Vervoort and colleagues ${ }^{1}$ are to be congratulated for their scoping review of access to cardiac surgical care around the world; indeed, they have provided important data about the scope of the challenge. In this editorial commentary, we have provided a summary of some of the ongoing efforts to address disparities in (1) the global availability of cardiothoracic surgical resources and (2) the global assessment of quality of cardiothoracic care. These ongoing efforts represent substantial contributions, but much work remains to be done!

\section{References}

1. Vervoort D, Meuris B, Meyns B, Verbrugghe P. Global cardiac surgery: access to cardiac surgical care around the world. J Thorac Cardiovasc Surg. 2020;159: 987-96.e6.

2. ResearchGate. Systematic review v Scoping review? Available at: https://www. researchgate.net/post/Systematic_review_Vs_Scoping_review. Accessed April $22,2019$.

3. Nguyen N, Jacobs JP, Dearani JA, Weinstein S, Novick WM, Jacobs ML, et al. Survey of nongovernmental organizations providing pediatric cardiovascular care in low- and middle-income countries. World J Pediatr Congenit Heart Surg. 2014;5: 248-55.

4. Dearani JA, Neirotti R, Kohnke EJ, Sinha KK, Cabalka AK, Barnes RD, et al Improving pediatric cardiac surgical care in developing countries: matching resources to needs. Semin Thorac Cardiovasc Surg Pediatr Card Surg Annu. 2010;13:35-43.

5. Dearani JA, Jacobs JP, Bolman RM III, Swain JD, Vricella LA, Weinstein S, et al Humanitarian outreach in cardiothoracic surgery: from setup to sustainability. Ann Thorac Surg. 2016;102:1004-11.

6. Hickey PA, Connor JA, Cherian KM, Jenkins K, Doherty K, Zhang H, et al International quality improvement initiatives. Cardiol Young. 2017;27(S6): S61-8.

7. St Louis JD, Kurosawa H, Jonas RA, Sandoval N, Cervantes J, Tchervenkov CI et al. The world database for pediatric and congenital heart surgery: the dawn of a new era of global communication and quality improvement in congenital heart disease. World J Pediatr Congenit Heart Surg. 2017;8:597-9. 